\title{
Epistaxis of patients admitted in the emergency department is not indicative of underlying arterial hypertension*
}

\author{
Petros Theodosis ${ }^{1}$, Maria Mouktaroudi ${ }^{2}$, Dimitrios Papadogiannis ${ }^{3}$, S. Ladas ${ }^{3}$, \\ S. Papaspyrou \\ ENT Department, General Hospital Of Athens "O Evagelismos", Athens, Greece \\ $4^{\text {th }}$ Department of Internal Medicine, University of Athens, Medical School, Greece \\ $1^{\text {st }}$ Department of Propedeutic Medicine, University of Athens, Medical School, Greece
}

\begin{abstract}
SUMMARY Objective: To assess the association between epistaxis and arterial hypertension.
Methods: A prospective study was conducted in 80 patients admitted in the emergency department, 42 with epistaxis and 38 well-matched controls. Blood pressure was measured upon admission and by continuous 24-hour ambulatory monitoring on the following days.

Results: Estimated values upon admission did not differ between groups. A definitive diagnosis of hypertension was set in 18 patients admitted for epistaxis (42.9\%) and in 11 controls (28.9\%, $p=N S$ ). Systolic pressures during the 24-hour recording period, systolic pressures during day and diastolic pressures during night were significantly higher among patients admitted for epistaxis than among controls.

Conclusions: Although studies with larger series of patients are mandatory, epistaxis does not seem to result from underlying arterial hypertension.
\end{abstract}

Key words: epistaxis, hypertension, ambulatory measurement

\section{INTRODUCTION}

Epistaxis is a frequent and sometimes serious and life threatening condition for the patient. Patients often present with hypertension which creates the need for differentiating between hypertension as an underlying cause of epistaxis and hypertension as an epiphenomenon attributed to stress ${ }^{(1)}$.

Hypertension is a common condition, estimated to cause $4.5 \%$ of current global disease burden ${ }^{(2)}$. Despite its high prevalence there is much debate as whether arterial hypertension may present with acute symptoms like epistaxis, headache, visual changes, chest pain and dyspnea ${ }^{(3)}$. This is particularly true for the symptom of epistaxis. Notwithstanding recent publications that suggest that epistaxis may be an warning sign of pre-existing arterial hypertension ${ }^{(4)}$, it is still doubtful whether a connection exists between epistaxis and hypertension. The present study was designed to provide further evidence to resolve this question.

\section{PATIENTS AND METHODS}

\section{Study type}

This is a prospective, observational study conducted in the Laikon General Hospital during the period January 2000January 2002. The study protocol was approved by the hospital's ethics committee. Exclusion criteria for the study were: a) any neoplasm of the nasal cavity; b) any injury of the nose; and c) any coagulation disorder.

\section{Patients}

Patients sequentially admitted to the emergency department of Laikon General Hospital participated in the study. A total of 80 patients were enrolled into two groups. Group A consisted of 42 patients admitted for epistaxis. Group B consisted of 38 patients who served as controls. These were admitted to the emergency department for one of three reasons: ear pain, headache and light head contusion. Light head contusion was considered in any patient who was admitted with lightheadness in the absence of head trauma after car crush in the absence of focal neurological signs and findings in brain computed tomography.

\section{Rhinoscopy}

After the patient's arrival to the emergency department, rhinoscopy was performed. More precisely, anterior rhinoscopy was done using a nasal speculum, a light source, and a head mirror with simple inspection. For posterior rhinoscopy a tongue depressor was placed on the center of the base of the tongue with one hand, and the base of the tongue was pressed downward. A small warmed mirror was then introduced into 
the space between the soft palate and posterior pharyngeal wall to inspect the choana, the posterior ends of the turbinates, the poisteriors margin of the septum, and the nasopharynx together with its roof and the ostia of the eustachian tube. Then epistaxis was managed with packing.

\section{Blood pressure measurement}

Following rhinoscopy and epistaxis management, the arterial pressure was measured as recommended ${ }^{(2)}$. Briefly, the patient was allowed to rest for at least 10 minutes. Then a trained nurse blind to the diagnosis of admission, measured the blood pressure three times using a mercuric manometer. The first value was rejected and the final result was calculated as the mean of the second and the third value. The procedure was repeated again after twenty minutes and the result given at the end was the mean value of the second and the third measurement.

After 10 to 20 days, when the stress of the epistaxis subsided, ambulatory blood pressure monitoring was initiated in a 24hour basis ${ }^{(5)}$ by using a Space Labs Model 90207 apparatus. None of the patients initially enrolled in the study was lost to follow-up. The personnel assessing the recordings were blinded to the diagnosis of admission. Diagnosis of arterial hypertension was based on systolic blood pressure greater than 140 $\mathrm{mmHg}$ during daytime and greater than $125 \mathrm{mmHg}$ during nighttime. Respective values for diastolic blood pressure were 90 and $75 \mathrm{mmHg}{ }^{(6)}$

\section{Further examination}

At the same time, a complete history was taken followed by ophthalmological examination of the retina and complete physical examination. Consequently, $10 \mathrm{ml}$ of blood was drawn under sterile conditions from a forearm antecubital vein; three $\mathrm{ml}$ were collected into an EDTA-coated tube (Vacutainer,
Becton Dickinson, Cockeysville, MD) for red blood cell, hemoglobin, white blood cell and platelet counting (Beckmann Coulter, Maimi, FL) and the remaining into a sterile tube. Blood was centrifuged and serum was applied for estimation of the biochemical parameters (Abbott, Chicago, IL) presented in Table 1.

\section{Statistics}

After defining that measurements followed normal distribution with Kolmogorov-Smirnov's statistics, results were expressed by their mean $\pm \mathrm{SD}$. Comparisons between groups were done by the Student's "t-test". Comparisons between groups for qualitative data were done by Chi-square-test. Any value of $\mathrm{p}<0.05$ was considered significant.

\section{RESULTS}

Demographic characteristics of patients enrolled in the study are shown in Table 1. The only significant differences between the two groups involved hemoglobin value and white blood cell count, which were higher in the controls, and serum LDL, which was higher in patients admitted for epistaxis.

Mean \pm SD systolic pressure of patients admitted in the emergencies with epistaxis was $177.7 \pm 49.1 \mathrm{mmHg}$; respective value of controls was $181.7 \pm 51.0 \mathrm{mmHg}$ ( $\mathrm{p}=\mathrm{NS}$ between groups). Mean \pm SD diastolic pressure of patients admitted in the emergencies with epistaxis was $93.1 \pm 30.0 \mathrm{mmHg}$; respective value of controls was $95.3 \pm 30.0 \mathrm{mmHg}$ ( $\mathrm{p}=$ NS between groups).

Continuous ambulatory estimation of blood pressure resulted in the diagnosis of arterial hypertension in 18 of patients admitted with epistaxis (42.9\%); only four of them were aware of their disease. Diagnosis of arterial hypertension was made by holter measurement in 11 of control patients (28.9\%); none

Table 1. Demographic and laboratory characteristics of patients enrolled in the study.

\begin{tabular}{|c|c|c|c|}
\hline & Epistaxis $(n=42)$ & Controls $(n=38)$ & $\mathrm{p}$ \\
\hline Sex (Male/Female) & $22 / 20$ & $18 / 20$ & 0.65 \\
\hline Age (years, mean $\pm \mathrm{SD}$ ) & $54.76 \pm 13.23$ & $50.26 \pm 14.56$ & 0.15 \\
\hline Weight $(\mathrm{kg}$, mean $\pm \mathrm{SD})$ & $75.9 \pm 8.2$ & $74.5 \pm 7.8$ & 0.15 \\
\hline Smoking (Number, $\%$ of patients) & $12(28.6)$ & $8(21.1)$ & 0.44 \\
\hline Height $(\mathrm{m}$, mean $\pm \mathrm{SD})$ & $1.71 \pm 0.08$ & $1.71 \pm 0.09$ & 0.80 \\
\hline Waist perimeter $(\mathrm{cm}$, mean $\pm \mathrm{SD})$ & $100.5 \pm 14.9$ & $95.6 \pm 14.7$ & 0.15 \\
\hline Hemoglobulin $(\mathrm{g} / \mathrm{dl}$, mean $\pm \mathrm{SD})$ & $12.98 \pm 1.35$ & $13.89 \pm 1.20$ & $<0.0001$ \\
\hline White blood cells $(/ \mu 1$, mean $\pm \mathrm{SD})$ & $5416.7 \pm 784.5$ & $5924.2 \pm 1001.3$ & 0.01 \\
\hline Platelets $(/ \mu 1$, mean \pm SD $)$ & $265976 \pm 44691$ & $291710 \pm 43290$ & 0.07 \\
\hline Glucose $(\mathrm{mg} / \mathrm{dl}$, mean $\pm \mathrm{SD})$ & $103.3 \pm 21.9$ & $104.5 \pm 20.1$ & 0.93 \\
\hline Urea $(\mathrm{mg} / \mathrm{dl}$, mean $\pm \mathrm{SD})$ & $36.45 \pm 6.93$ & $34.68 \pm 4.85$ & 0.19 \\
\hline Creatinine $(\mathrm{mg} / \mathrm{dl}$, mean $\pm \mathrm{SD})$ & $1.07 \pm 0.19$ & $1.06 \pm 0.19$ & 0.76 \\
\hline Sodium $(\mathrm{mEq} / 1$, mean $\pm \mathrm{SD})$ & $140.3 \pm 5.9$ & $139.4 \pm 3.1$ & 0.42 \\
\hline Total cholesterol $(\mathrm{mg} / \mathrm{dl}$, mean $\pm \mathrm{SD})$ & $190.9 \pm 27.9$ & $192.2 \pm 23.8$ & 0.83 \\
\hline $\mathrm{LDL}(\mathrm{mg} / \mathrm{dl}$, mean $\pm \mathrm{SD})$ & $134.4 \pm 14.5$ & $119.5 \pm 21.2$ & 0.001 \\
\hline $\mathrm{HDL}(\mathrm{mg} / \mathrm{dl}$, mean $\pm \mathrm{SD})$ & $59.8 \pm 10.1$ & $63.5 \pm 11.3$ & 0.13 \\
\hline Triglycerides $(\mathrm{mg} / \mathrm{dl}$, mean $\pm \mathrm{SD})$ & $162.1 \pm 57.8$ & $163.3 \pm 55.2$ & 0.93 \\
\hline
\end{tabular}


was aware of its presence ( $\mathrm{p}=$ NS between the two groups). Results of continuous ambulatory measurement of arterial pressure of both groups are shown in Table 2. Systolic pressures during the 24-hour recording period, systolic pressures during day and diastolic pressures during night were significantly higher among patients admitted for epistaxis than among their controls.

\section{DISCUSSION}

The present study was designed to provide a definite answer to the query whether epistaxis may be a symptom related to the underlying presence of arterial hypertension of not. Blood pressure was measured in 42 patients admitted in the emergency department (ED) for epistaxis and compared with 38 patients admitted for reasons other than epistaxis. Both groups were well matched for gender, age, smoking habits and laboratory parameters. Measurement in the ED was followed by 24hour continuous ambulatory measurement. All patients enrolled in the study, whether they had epistaxis or not, were admitted with high levels of both systolic and diastolic blood pressure; no difference was documented between the two groups. It may be hypothesized that these high levels may be connected with the stress of the patients visiting the ED.

After 24-hour blood pressure monitoring, patients admitted with epistaxis were found with elevated systolic pressures compared to controls, an observation mainly involving measurements performed during day (Table 2). On the same context, similar differences in measurements of diastolic pressure during night were encountered. Despite these recorded differences, a final diagnosis of hypertension was set in $42.9 \%$ of patients admitted with epistaxis and in $28.9 \%$ of controls, which was not a statistically significant difference. The latter lack of difference creates serious doubts as to whether a connection of epistaxis with arterial hypertension may exist based on the presented findings. It should be underscored that patients with epistaxis were presented with greater levels of LDL compared with their controls (Table 1). As a consequence, a greater rate of atherosclerosis among them cannot be excluded.

The presented results are in agreement with those of a trial by Herkner et al. in a population of 213 admissions in the ED for epistaxis ${ }^{(7)}$. Hundred and eight patients (50.7\%) presented with elevated systolic blood pressure, in 33 of which (15.5\%) arterial hypertension was subsequently diagnosed. Application of 24hour holter recording in the latter patients disclosed hypertension in $12.2 \%$ of the initially enrolled patients for epistaxis.

Three comparative trials have been published trying to asssess the association between epistaxis and arterial hypertension. Two of them have a prospective design and the third one a retrospective design. Fuchs et al. failed to establish any connection between epistaxis and hypertension in a total population of 1174 individuals ${ }^{(8)}$. Similar results were drawn by Karras et al. in a population of 1908 individuals ${ }^{(3)}$. However, a retrospective analysis of 271 patients admitted in the ED for epistaxis compared with 101 controls disclosed that the odds ratio for epistaxis was 2.8 among patients with a history of hypertension, which was statistically significant $(\mathrm{p}=0.004)$. However, in none of the above three trials continuous ambulatory 24-hour blood pressure monitoring was performed, as occurred with the present study design.

Despite the limited number of patients enrolled in the present study, it was evident that systolic blood pressure was elevated among patients admitted in the ED for epistaxis compared to controls. However, these levels failed to discern a final diagnosis of hypertension with safety. In fact, the rate of a final diagnosis of hypertension did not differ between groups. Although our findings create serious concerns whether epistaxis constitutes a symptom related to underlying arterial hypertension, they are not definitive due to the limited num-

Table 2. Results of ambulatory 24-hour blood pressure monitoring of patients.

\begin{tabular}{|c|c|c|c|}
\hline & Epistaxis $(n=42)$ & Controls $(n=38)$ & $\mathrm{p}$ \\
\hline $\begin{array}{l}\text { Systolic pressure for } 24 \text { hours } \\
(\mathrm{mmHg} \text {, mean } \pm \mathrm{SD})\end{array}$ & $129.19 \pm 11.35$ & $123.16 \pm 13.94$ & 0.04 \\
\hline $\begin{array}{l}\text { Diastolic pressure for } 24 \text { hours } \\
(\mathrm{mmHg}, \text { mean } \pm \mathrm{SD})\end{array}$ & $76.81 \pm 7.69$ & $73.53 \pm 0.08$ & 0.07 \\
\hline $\begin{array}{l}\text { Systolic pressure during day } \\
(\mathrm{mmHg}, \text { mean } \pm \mathrm{SD})\end{array}$ & $132.57 \pm 11.50$ & $125.89 \pm 15.24$ & 0.03 \\
\hline $\begin{array}{l}\text { Diastolic pressure during day } \\
(\mathrm{mmHg}, \text { mean } \pm \mathrm{SD})\end{array}$ & $79.48 \pm 8.07$ & $75.92 \pm 9.91$ & 0.08 \\
\hline $\begin{array}{l}\text { Systolic pressure during night } \\
(\mathrm{mmHg} \text {, mean } \pm \mathrm{SD})\end{array}$ & $121.00 \pm 13.12$ & $115.50 \pm 14.95$ & 0.05 \\
\hline $\begin{array}{l}\text { Diastolic pressure during night } \\
(\mathrm{mmHg}, \text { mean } \pm \mathrm{SD})\end{array}$ & $70.79 \pm 9.37$ & $66.21 \pm 7.70$ & 0.02 \\
\hline $\begin{array}{l}\text { Pulse rate during day } \\
(/ \mathrm{min}, \text { mean } \pm \mathrm{SD})\end{array}$ & $79.19 \pm 11.12$ & $74.55 \pm 10.67$ & 0.05 \\
\hline $\begin{array}{l}\text { Pulse rate during night } \\
(/ \min , \text { mean } \pm \mathrm{SD})\end{array}$ & $68.40 \pm 9.06$ & $66.61 \pm 9.93$ & 0.40 \\
\hline
\end{tabular}


ber of enrolled patients. A larger series is mandatory to fully address this question.

\section{REFERENCES}

1. Denholm SW, Maynard CA, Watson HG. Warfarin and epistaxis-a case controlled study. J Laryngol Otol 1993; 107: 195-196.

2. Panagiotakos DB, Pitsavos CH, Chrysohoou C, Skoumas J, Papadimitriou L, Stefanadis C, Toutouzas PK. Status and management of hypertension in Greece: role of the adoption of a Mediterranean diet: the Attica study. J Hypertens 2003; 21:14831489 .

3. Karras DJ, Ufberg JW, Harrigan RA, Wald DA, Botros MS, McNamara RM. Lack of relationship between hypertension-associated symptoms and blood pressure in hypertensive ED patients. Am J Emerg Med 2005; 23: 106-110.

4. Herkner H, Havel C, Müllner M, Gamper G, Bur A, Temmel AF, Laggner AN, Hirschl MM: Active epistaxis at ED presentation is associated with arterial hypertension. Am J Emerg Med 2002; 20: 92-95.

5. Godwin M, Delva D, Seguin R, Casson I, MacDonald S, Birtwhistle R, Lam M: Relationship between blood pressure measurements recorded on patients' charts in family physicians' offices and subsequent 24 hour ambulatory blood pressure monitoring. BMC Cardiovasc Disord 2004; 4: 2.
6. O'Brien E. Ambulatory blood pressure monitoring in the management of hypertension. Heart 2003; 89: 571-576.

7. Herkner H, Laggner AN, Müllner M, Formanek M, Bur A, Gamper G, Woisetschläger C, Hirschl MM: Hypertension in patients presenting with epistaxis. Ann Emerg Med 2000; 35: 126130.

8. Fuchs FD, Moreira LB, Pires CP, Torres FS, Furtado MV, Moraes RS, Wiehe M, Fuchs SC, Lubianca Neto JF: Absence of association between hypertension and epistaxis: a population-based study. Blood Press 2003; 12: 145-148.

\section{Petros Theodosis}

ENT Department

General Hospital Of Athens "O Evagelismos"

Aristotelous 182

Athens

Greece

Tel: +30-697-485 5558

E-mail: P.Theodosis@yahoo.gr 